\title{
Like Oil and Water: The Politics of (Not) Assessing Glyphosate Concentrations in Aquatic Ecosystems
}

\author{
Yogi Hale HENDLIN*(i), Alessandra ARCURI**, Robert LEPENIES*** and \\ Frank HÜESKER****
}

Since the International Agency on Cancer Research's monograph found glyphosate to be a likely carcinogen, the regulatory focus on the chemical has centred on this determinative criterion for regulatory action. Yet, other pertinent factors, such as the effects of glyphosate on fresh and ground water and ensuing effects on biodiversity, have received less attention as legitimate rationales for regulating the chemical. This underrepresentation prevents a wider policy discussion on the environmental and human health effects of the chemical and fails to disrupt assumptions of path-dependently continuing on agriculture's chemical treadmill. To avoid ad hoc post hoc chemical regulation, we assess four areas of chemical regulatory oversight in Europe with regard to glyphosate affecting water: (1) the undue emphasis on in laboratorio versus in situ testing; (2) assessing single chemicals (isolated glyphosate) versus admixtures (glyphosate plus surfactants and adjuvants) that are used in practice; (3) the tendency to downplay harms to nonhuman life; and (4) the lack of policy coherence in the existing regulatory framework. Focusing on European Union regulation of pesticide and water policy affecting aquatic environments, we conclude that issues of measurement and priority have become highly politicised in both science and policy, requiring preventative, precautionary frameworks utilising plural forms of measurement.

\section{INTRODUCTION}

Environmental risk assessments often overlook the structural and systemic "grounded social causes of precarity that expose and sensitize people to hazard". ${ }^{1}$ A chemical's hazard is derived from both its intrinsic properties to interact and affect biological material in a controlled setting as well as relational harms when that chemical

\footnotetext{
* Dynamics of Inclusive Prosperity Initiative, Erasmus School of Philosophy, Erasmus University Rotterdam, Rotterdam, The Netherlands and Environmental Health Initiative, University of California, San Francisco, CA, USA, email: hendlin@esphil.eur.nl. We would like to thank the Erasmus University Rotterdam's Dynamics of Inclusive Prosperity Initiative and Institute for Public Knowledge for their financial and organisational support for the 6 June 2019 "The Science and Politics of Glyphosate" Workshop that Yogi Hale Hendlin and Alessandra Arcuri organised, which occasioned this special issue and the development of this article. We have no conflicts of interest to disclose.

** Inclusive Global Law and Governance, Erasmus School of Law and Erasmus Initiative Dynamics of Inclusive Prosperity, Erasmus University Rotterdam, Rotterdam, The Netherlands.

*** Helmholtz-Centre for Environmental Research - UFZ, Department of Environmental Politics, Leipzig, Germany.

**** Helmholtz-Centre for Environmental Research - UFZ, Department of Environmental Politics, Leipzig, Germany.

1 J Ribot, "Cause and Response: Vulnerability and Climate in the Anthropocene" (2014) 41 The Journal of Peasant Studies 667,668 .
} re-use, distribution, and reproduction in any medium, provided the original work is properly cited. 
interacts with different organisms and chemicals in admixtures rather than in isolation. Chemical assessments frequently pay more attention to the former rather than latter hazards, possibly underestimating real-world risks. Virtually all chemical exposures occur together with other chemicals, with interactions affecting organisms variously depending on exposure combinations. Especially in different media such as water or soil, rather than being inert, chemicals degrade or potentiate in as-yet unstudied ways. Against this background, this article considers how the legal and policy frameworks for the assessments of glyphosate - the most used herbicide in history - tend to deemphasise the assessment of its effects on fresh water. Doing so also entails interpreting the limits of current legal frameworks in the European Union (EU) to address the risks of freshwater contaminations by pesticides. This paper claims that the EU regulatory system currently does not adequately protect aquatic ecosystems from pesticide contamination, substantiated through analysing the case of glyphosate.

Agrochemical runoff damage to freshwater systems has been identified as a major threat to wildlife, ecosystems and securing clean drinking water for populations in European countries ${ }^{2}$ and globally. ${ }^{3}$ Widespread use of fertilisers, pesticides and herbicides in the twentieth and twenty-first centuries is documented in the corresponding chemical signatures found in aquatic environments globally. ${ }^{4}$ Until stronger environmental regulations began being implemented in the 1960s and 1970s, post-war chemical effluent was regularly dumped without reflection or legal restriction, often harming riparian life and sometimes contaminating ground water. ${ }^{5}$ While during this early period of environmental regulation the USA led international policy diffusion on freshwater protections, ${ }^{6}$ by the 1990s Europe had taken the regulatory lead, and it is currently perceived to be at the forefront of water protection, both in terms of regulations and enforcement. ${ }^{7}$ Europe's embrace of integrated chemical management and policy has allowed for increased environmental health, and through its relation, human health. ${ }^{8}$ Nevertheless, European water quality is in bad shape: together with near-ubiquitous crop over-fertilisation and loss of habitat due to

\footnotetext{
2 MA Beketov et al, "Pesticides Reduce Regional Biodiversity of Stream Invertebrates" (2013) 110 Proceedings of the National Academy of Sciences 11039; M Liess and PC Von Der Ohe, "Analyzing Effects of Pesticides on Invertebrate Communities in Streams" (2005) 24 Environmental Toxicology and Chemistry 954.

3 WA Battaglin et al, "Glyphosate and Its Degradation Product AMPA Occur Frequently and Widely in U.S. Soils, Surface Water, Groundwater, and Precipitation" (2014) 50 Journal of the American Water Resources Association 275; C Revenga and World Resources Institute (eds), Pilot Analysis of Global Ecosystems: Freshwater Systems (Washington, DC, World Resources Institute 2000).

$4 \mathrm{CH}$ Vane et al, "Chemical Signatures of the Anthropocene in the Clyde Estuary, UK: Sediment-Hosted Pb, ${ }^{207 / 206} \mathrm{~Pb}$, Total Petroleum Hydrocarbon, Polyaromatic Hydrocarbon and Polychlorinated Biphenyl Pollution Records" (2011) 369 Philosophical Transactions of the Royal Society A: Mathematical, Physical and Engineering Sciences 1085.

5 IM Sayre, "International Standards for Drinking Water" (1988) 80 Journal - American Water Works Association 53.

6 D Kelemen and D Vogel, "Trading Places: The Role of the United States and the European Union in International Environmental Politics” (2010) 43 Comparative Political Studies 427.

7 S Vaughan, EU Chemicals Regulation: New Governance, Hybridity and REACH (Cheltenham, Edward Elgar Publishing 2015); SF Hansen, L Carlsen and JA Tickner, "Chemicals Regulation and Precaution: Does REACH Really Incorporate the Precautionary Principle” (2007) 10 Environmental Science \& Policy 395.

8 Strategic Approach to International Chemicals Management (SAICM), Strategic Approach to International Chemicals Management: Comprising the Dubai Declaration on International Chemicals Management, the Overarching Policy Strategy and the Global Plan Action: Resolution of the International Conference on Chemicals Management (Nairobi, United Nations Environment Programme 2006).
} 
morphological changes, agrochemical inputs are degrading freshwater quality throughout Europe, by some accounts reducing ecosystem functions by over $20 \%$. ${ }^{9}$ Thus, one would expect that glyphosate regulation, in addition to attending to important issues raised regarding direct human health questions, would take into serious consideration how it affects water quality.

Based on the central role for health that water plays, such regulation would draw on the assumed extensive research analysing the risks of glyphosate in impacting the health of aquatic ecosystems. Yet compared to other scientific domains scrutinizing this chemical, there are surprisingly few field studies on glyphosate's effects in and on fresh water. Most existing research in this area seems to not account for the adjuvants in commercial glyphosate admixtures, such as RoundUp®, leaving out crucial consequences of how chemical mixtures affect various domains. In examining how European law assesses chemical risk in surface water and ground water, this article emphasises the politics and consequences of measuring the ecotoxicity of chemicals like glyphosate in isolation rather than according to their interactions. Focusing on the impact of glyphosate on aquatic ecosystems and the policies around chemicals in water both in the special case of glyphosate and more generally, we hypothesise that the legal and scientific assessment processes are fraught with blind spots. While clearly we cannot look at all of the gaps here, we point out some of the blind spots specifically in chemical regulation (using glyphosate as a model case) in the EU pertaining to effects and interactions with fresh water. ${ }^{10}$

This contribution assesses the discursive and regulatory context surrounding the measurement and assessment of glyphosate's impacts on aquatic environments, rather than exhaustively weighing the biodiversity impact of glyphosate and its coconstituent chemicals on aquatic life from a natural science perspective. It is structured as follows: in Section II, we start by presenting some data on glyphosate contamination in surface water and ground water; we then offer an overview of the debate that has ensued among scientists and technical regulatory bodies vis-à-vis the methodologies used to assess the effects of glyphosate in aquatic ecosystems. In this context, it has been argued that taking a single-metric approach to detection may predictably pass over other chemical combinations occurring in water (ie from adjuvants, as well as through degradation and reactions with other present chemicals), which is related to the fact that relevant guidance documents in the ecotoxicological

\footnotetext{
9 M-S Javier et al, Water Pollution from Agriculture: A Global Review. Executive Summary (FAO Colombo, Sri Lanka, International Water Management Institute (IWMI) CGIAR Research Program on Water, Land and Ecosystems (WLE) 2017); K Peters, M Bundschuh and RB Schäfer, "Review on the Effects of Toxicants on Freshwater Ecosystem Functions" (2013) 180 Environmental Pollution 324; PC von der Ohe et al, "Water Quality Indices across Europe - A Comparison of the Good Ecological Status of Five River Basins" (2007) 9 Journal of Environmental Monitoring 970; C Stoate et al, "Ecological Impacts of Arable Intensification in Europe" (2001) 63 Journal of Environmental Management 337.

10 SO Funtowicz and JR Ravetz, "Three Types of Risk Assessment and the Emergence of Post-Normal Science" in S Krimsky and D Golding (eds), Social Theories of Risk (Westport, CT, Praeger 1992) pp 251-74; S Jasanoff, "Science, Politics, and the Renegotiation of Expertise at EPA" (1992) 7 Osiris 194; S Jasanoff, "Technologies of Humility: Citizen Participation in Governing Science" in A Bogner and H Torgersen (eds), Wozu Experten? (VS Verlag für Sozialwissenschaften 2005) <http://link.springer.com/10.1007/978-3-322-80692-5_17> (last accessed 1 June 2020).
} 
risk assessment process leave ample room for interpretation. ${ }^{11}$ The dominance of this single-metric approach is so powerful that its narrow scope has become systemdefining and entrenched in the scientific, political and legal formats, rendering effects not fitting this model largely illegible to these domains of enquiry. ${ }^{12}$

In Section III, we show how environmental protections of aquatic environments are present in European law, but often receive superficial or secondary attention in practice. We argue that this is because in the EU legal system, important issues such as schemes for reducing pesticide quantities are neglected. Overall, we find that regulatory policy structurally deprioritises water legislation and water politics vis-àvis other political and economic issues. This systematic ambiguity regarding the protection of aquatic ecosystem health in legal and political discourse has been documented as subsumed under heading of "anthropocentrism" in the chemical Anthropocene. ${ }^{13}$

Finally, in Section IV, we reflect on the discrepancies between the regulations for aquatic contamination and the implementation of these policies in practice. Ecotoxicological assessments emphasise the importance of ensuring that no unacceptable harms come from chemical application, and yet the actual discrepancies between which outcomes are in fact deemed acceptable rarely gets fed back into the policy process. ${ }^{14}$ We further discuss how the current deficient legal framework is situated in a broader socioeconomic system and can be understood as part and parcel of this system. While enforcement questions bear on the regulatory systems involved, analysing enforcement is outside the scope of this paper. When analysing these discrepancies, we also draw on prior theoretical insights from the literatures of science and technology studies and politics of science advice. ${ }^{15}$

In addressing these questions through the case of glyphosate and its associated products, we enquire into how "compartmentalising" risk serves to underestimate the transversal actual hazards that chemicals catalyse in waterways for humans and other organisms. Compartmentalisation occurs both in the separation of risk assessment and

\footnotetext{
11 C Robinson et al, "Achieving a High Level of Protection from Pesticides in Europe: Problems with the Current Risk Assessment Procedure and Solutions" (2020) European Journal of Risk Regulation DOI: 10.1017/err.2020.18; R Altenburger et al, "Future Water Quality Monitoring - Adapting Tools to Deal with Mixtures of Pollutants in Water Resource Management" (2015) 512-13 Science of the Total Environment 540; R Altenburger et al, "Future Water Quality Monitoring: Improving the Balance between Exposure and Toxicity Assessments of Real-World Pollutant Mixtures" (2019) 31 Environmental Sciences Europe 12; L Posthuma et al, "Mixtures of Chemicals Are Important Drivers of Impacts on Ecological Status in European Surface Waters" (2019) 31 Environmental Sciences Europe 71.

12 D Demortain, "Expertise, Regulatory Science and the Evaluation of Technology and Risk: Introduction to the Special Issue" (2017) 55 Minerva 139.; A Arcuri and YH Hendlin, "The Chemical Anthropocene: Glyphosate as a Case Study of Pesticide Exposures" (2019) 30 King's Law Journal 234; JC Scott, Seeing Like a State: How Certain Schemes to Improve the Human Condition Have Failed (New Haven, CT, Yale University Press 1999); G Markowitz and D Rosner, Deceit and Denial: The Deadly Politics of Industrial Pollution (Berkeley, University of California Press 2002).

13 Arcuri and Hendlin, supra, note 12.

14 US Environmental Protection Agency, "Summary of the Federal Insecticide, Fungicide, and Rodenticide Act" (US EPA, 22 February 2013) <https://www.epa.gov/laws-regulations/summary-federal-insecticide-fungicide-androdenticide-act $>$ (last accessed 8 March 2020). The manufacturer must show that a pesticide "will not generally cause unreasonable adverse effects on the environment".

15 Jasanoff, "Science, Politics, and the Renegotiation of Expertise at EPA", supra, note 10; Jasanoff, "Technologies of Humility", supra, note 10; Funtowicz and Ravetz, supra, note 10.
} 
management and in the separation of the active substance glyphosate from real-world blended chemicals. Here, we focus on the authorisation of the active substance on the European level and, to a lesser extent, on the authorisation of plant protection products (PPPs) at the EU Member State level - rather than on other aspects of pesticide politics, such as retail or application. Pesticide politics is complex. But the two-fold EU authorisation process is particularly complex and has been demonstrated as being determinative in making sense of other aspects of chemical regulation. ${ }^{16}$

In this contribution, we specifically focus on the various reductionist modes of pesticide risk assessment that justify downstream authorisation. The compartmentalisation of risk assessments based primarily on in laboratorio data on a given isolated chemical versus the complicated relation of these to messy in situ field and epidemiological data leads to the perverse valuation of models of chemical toxicity over the actual effects that these chemicals have in interaction with other chemicals, other substrates such as water and the varying experiences of biological life. In situ (higher-tier) experiments, however, produce higher ranges of uncertainty regarding the absence of harm - even harms that are actually present. Paradoxically, by trying to make regulatory tests of chemicals more representative of reality, risk assessment tends towards permissiveness in terms of authorising harmful chemicals.

To reach these conclusions, we drew on document analysis, desk research and a nonsystematic literature search (including, for instance, a web search for position statements on glyphosate and water by regulatory agencies at the EU level and in selected Member States - all major position statements and opinion pieces that contain mention of glyphosate and biodiversity). This article does not pretend to be a granular critique of the technicalities of the risk assessment procedure (ie comparing contrastive guidance documents), nor does it propose a cohesive plan to refashion chemical regulatory processes with respect to water. Instead, our findings offer key avenues for further research, pointing out for political scientists and legal scholars areas for investigating weaknesses at the intersection of pesticides and water regulation.

\section{THE PRESENCE OF GLYPHOSATE IN WATER AND ITS IMPACT ON ECOSYSTEMS}

Narratives of how - even whether - pesticides impact (aquatic) ecosystems seem to be neatly aligned with different positions on the role of industrial agriculture. ${ }^{17}$ This section explores the risks of glyphosate for aquatic ecosystems - chemical impacts on ecosystem functionality or biodiversity - highlighting specific controversies as debated in environmental science and policy.

16 D Demortain, "Expertise, Regulatory Science and the Evaluation of Technology and Risk: Introduction to the Special Issue” (2017) 55 Minerva 139.

17 H Muilerman, "Industry Writing Its Own Rules" (Pesticide Action Network Europe, 6 February 2018) <https:// www.pan-europe.info/press-releases/2018/02/industry-writing-its-own-rules> (last accessed 5 May 2020); E Bozzini, “Open Controversies: Bees' Health, Glyphosate and Endocrine Disruption" in E Bozzini, Pesticide Policy and Politics in the European Union (Cham, Springer International Publishing 2017) <http://link.springer.com/10.1007/978-3-31952736-9_4> (last accessed 6 March 2020); JR Rohr, "Atrazine and Amphibians: A Story of Profits, Controversy, and Animus", Encyclopedia of the Anthropocene (Amsterdam, Elsevier 2018) <https://linkinghub.elsevier.com/ retrieve/pii/B9780128096659098852> (last accessed 3 March 2020). 
Pesticides like herbicides (herbicides are here considered a subset of pesticides) applied to crops impact soil, agricultural irrigation channels and runoff. ${ }^{18}$ Runoff from these applications has different impacts on varying types of aquatic environments, such as ground water, rivers, wetlands and reservoirs. Both direct and indirect runoff can affect water in proportion to the amount of chemicals applied, how focused they are sprayed on plants, the adhesives or adjuvants in the chemical and the size and ecological structure of the water system.

Europe is an outlier globally in terms of peak concentrations for glyphosate in waterbodies. In Europe, there are persistent but low concentrations of glyphosate. In many other global regions, peak concentrations sometimes reach up to 10,000 times the concentration of average EU levels. ${ }^{19}$ While ecotoxicologists in Europe acknowledge that glyphosate exacerbates and compounds multiple environmental stressors and water quality issues,$^{20}$ they simultaneously fear that likely alternative replacement chemicals, which would make their way through prevailing chemical regulation frameworks, could be even more environmentally harmful - if agricultural production continues unchanged. ${ }^{21}$ This suggests that plans to make EU glyphosate-free must also be accompanied by the larger challenge of reducing chemical inputs in agriculture in general; and that failing to address these issues in tandem may land regulators in the same tight spot they find themselves in with glyphosate, only next time with glyphosate's successor. ${ }^{22}$

Various statutes and laws in national and EU legislation protect water from chemical runoff, all of which have fundamental strengths and flaws. The central piece of legislation on water quality, with an ambitious schedule and a reporting system that has re-orientated water management approaches throughout Europe, is the EU Water Framework Directive (WFD). Its twin objectives stipulate that European waterbodies should be in good chemical and ecological condition. Pesticides (including herbicides such as glyphosate) can be found to violate these objectives in waterbodies either by exceeding environmental quality standards (EQSs; chemical status) or by significantly impacting the ecology of a waterbody (ecological status). Notably, glyphosate is not among the substances of the EU WFD's daughter directive on EQSs for surface waters 2008/105/EC, which sets limits and monitoring obligations for around forty-five specifically hazardous chemical substances (not only pesticides). As it is formally a EU directive that specifies certain substances rather than others, the decision-making process is highly political: if a Member State fails to limit only

\footnotetext{
18 S Stehle and R Schulz, "Pesticide Authorization in the EU - Environment Unprotected?" (2015) 22 Environmental Science and Pollution Research 19632.

19 Battaglin et al, supra, note 3.

20 A Szekacs and B Darvas, "Forty Years with Glyphosate" in MN Hasaneen (ed.), Herbicides - Properties, Synthesis and Control of Weeds (London, InTech 2012) <http://www.intechopen.com/books/herbicides-properties-synthesis-andcontrol-of-weeds/forty-years-with-glyphosate> (last accessed 11 March 2020); M Sihtmäe et al, "Ecotoxicological Effects of Different Glyphosate Formulations" (2013) 72 Applied Soil Ecology 215.

21 SO Duke and SB Powles, "Glyphosate: A Once-in-a-Century Herbicide" (2008) 64 Pest Management Science 319; JP Myers et al, "Concerns over Use of Glyphosate-Based Herbicides and Risks Associated with Exposures: A Consensus Statement" (2016) 15 Environmental Health: A Global Access Science Source 19; Bayer, "Glyphosate's Role in Preserving the Environment and Biodiversity" (Bayer Global, 10 March 2020) <https://www.bayer.com/en/ glyphosate-environment-biodiversity.aspx > (last accessed 26 June 2020).

22 J Allen, "Stop Playing Whack-a-Mole with Hazardous Chemicals" (Washington Post, 15 December 2016) $<$ https://www.washingtonpost.com/opinions/stop-playing-whack-a-mole-with-hazardous-chemicals/2016/12/15/ 9a357090-bb36-11e6-91ee-1adddfe36cbe_story.html> (last accessed 16 December 2019).
} 
one of forty-five substances, then the whole regulation of the chemical status is regarded as failed for a specific monitoring period. In other words, to regulate a substance through this directive requires a high degree of consensus on the chemical's danger to reach the threshold of regulation. Likewise, the directive is predominantly formulated to apply to large waterbodies and the chemicals found therein, which means that smaller streams common in agricultural landscapes are often excluded from river basin management plans. Despite the lack of systematic monitoring of glyphosate residues in water, evidence has emerged as to its presence in Europe. In its Report on Glyphosate, the European Food Safety Authority (EFSA) acknowledges that glyphosate and its metabolite aminomethylphosphonic acid (AMPA; which maintains the same properties of glyphosate but is more persistent) have been found in a number of countries above the parametric limits. Italy is a case in point, where a study by the Italian Higher Institute for Environmental Protection and Research (ISPRA) in the "National Report of Pesticides in Water" found that "[i]n surface waters, 274 points of monitoring (21.3\% of the total) show glyphosate concentrations above the limits imposed to guarantee environmental quality standards". ${ }^{23}$

Similar to the political debate around glyphosate, ${ }^{24}$ aspects of the scholarly debate within ecotoxicology have been extraordinarily heated regarding the extent to which glyphosate-containing products harm aquatic ecosystems. ${ }^{25}$ In an unusually hostile academic exchange in the journal Ecological Applications, two groups of authors have accused each other of unscientific behaviour - claiming that Roundup ${ }^{\circledR}$ is either generally harmful or generally safe for amphibians. Contributors to this and subsequent debates have sought to disqualify the other's research by pointing out the role of corporate or non-governmental organisation (NGO) funding influencing the neutrality of their assessments. ${ }^{26}$ At the centre of the controversy were claims

\footnotetext{
23 P Paris et al, "Rapporto Nazionale dei Pesticidi Nelle Acque" (ISPRA, April 2018) < http://www.isprambiente.gov. it/en/publications/reports/national-report-on-pesticides-in-water-2013-2015-2016-data > (last accessed 28 June 2020).

24 J Tosun, H Lelieveldt and TS Wing, “A Case of 'Muddling Through'? The Politics of Renewing Glyphosate Authorization in the European Union" (2019) 11 Sustainability 440.

25 RA Relyea, "The Impact of Insecticides and Herbicides on the Biodiversity and Productivity of Aquatic Communities: Response" (2006) 16 Ecological Applications 2027; RA Relyea, "Amphibians Are Not Ready for Roundup®" in JE Elliott, CA Bishop and CA Morrissey (eds), Wildlife Ecotoxicology: Forensic Approaches (Berlin, Springer 2011) pp 267-300; DG Thompson et al, "The Impact of Insecticides and Herbicides on the Biodiversity and Productivity of Aquatic Communities" (2006) 16 Ecological Applications 2022; JP Giesy, S Dobson and KR Solomon, "Ecotoxicological Risk Assessment for Roundup® Herbicide" in GW Ware (ed.), Reviews of Environmental Contamination and Toxicology: Continuation of Residue Reviews (Berlin, Springer 2000) $<$ https://doi.org/10.1007/978-1-4612-1156-3_2> (last accessed 3 March 2020).

26 Research has shown the existence of a funding effect. See S Krimsky, "Do Financial Conflicts of Interest Bias Research? An Inquiry into the "Funding Effect" Hypothesis" (2013) 38(4) Science, Technology \& Human Values 566. In this context, it is worth mentioning the questionable symmetry that corporate-funded researchers assume between their private profit-seeking corporate funding versus researchers funded by NGOs with missions to protect public health and the environment. This parallel assumes comparable goal-directedness. Yet, should an industry-funded researcher be influenced by their funding source, the tendency would be to underreport the actual harms of a substance, leading to potentially substantial health harms; should an environmental or health NGO-funded researcher be influenced by their funding source, their tendency would be to err on the side of precaution, creating a buffer between possible public health and environmental harms. For the latter, over-precaution would hurt the profits of a given private corporation and hinder farmers locked into industrial agriculture, but would favour reduction of material, physical and distributed harms over a larger group of stakeholders (often with consequent health harms skewing towards impacting those most economically and otherwise discriminated against in a given society). From a normative perspective, some funding effects may be less desirable than others. The above does not account for other forms of asymmetry, including the vastly unequal amount of industry funding aimed at proving the salience and safety of their products, which is orders of magnitude larger than NGO and state research funding investigating the safety of chemicals.
} 
regarding Roundup $®$, the top-selling herbicide product containing glyphosate as its active compound, as well as the surfactant polyoxyethyleneamine (POEA) and its impact on lethality to tadpoles (with the claim being: "Amphibians Are Not Ready for Roundup ${ }^{\circledR}$ "). ${ }^{27}$ Here, the discussion has focused on the so-called "inert" ingredients/additives that are part of commercial formulations of herbicides. To penetrate leaves and to stick to them rather than washing off, Monsanto (now Bayer) has insisted on the need for such additives. ${ }^{28}$ Inert ingredients are typically trade secrets, and the academic discussion has focused on the core issue that the products used outside the laboratory and in the field are a combination of a highly scrutinised substance (glyphosate) and under-regulated additives that makes the product highly toxic to amphibians (eg which penetrate through tadpole gill cells). Critics see a pattern in the risk assessment systematically underestimating the harm of adjuvants. ${ }^{29}$ Similar intra-scientific controversies have occurred related to a different herbicide, atrazine, where a similar drama unfolded with accusations of corporate sponsoring of "industrial product defence research" and eco-activist research. ${ }^{30}$ While the glyphosate and atrazine cases may be the most notable discussions in the literature, in mainstream ecotoxicology building on field studies, it is increasingly clear that there are negative effects on aquatic biodiversity or freshwater ecosystem functions from pesticides more generally. ${ }^{31}$

A non-systematic search demonstrates the range of ecological effects for which glyphosate has been implicated in the toxicology literature. Glyphosate's direct toxic effects have been described as lethal ${ }^{32}$ to affected organisms such as amphibians or pollywogs, or sub-lethal ${ }^{33}$ but leading to dysergistic (negative synergy) impairment to affected organisms such as honeybees, spiders and lacewings. ${ }^{34}$ As described by the German Federal Agency for Nature Protection (BfN) in their remarkable position paper on glyphosate, ${ }^{35}$ the two main ways glyphosate can impact biodiversity are

27 Relyea, “Amphibians Are Not Ready for Roundup®”, supra, note 25.

28 R Mesnage, C Benbrook and MN Antoniou, "Insight into the Confusion over Surfactant Co-Formulants in Glyphosate-Based Herbicides" (2019) 128 Food and Chemical Toxicology 137; DE Riechers et al, "Surfactant Effects on Glyphosate Efficacy" (1995) 9 Weed Technology 281.

29 Robinson et al, supra, note 11.

30 Rohr, supra, note 17; MD Boone et al, "Pesticide Regulation amid the Influence of Industry" (2014) 64 BioScience 917.

31 RB Schäfer, "Responses of Freshwater Macroinvertebrates to Pesticides: Insights from Field Studies" (2019) 11 Current Opinion in Environmental Science \& Health 1; Peters et al, supra, note 9; RB Schäfer et al, "Effects of Pesticides on Community Structure and Ecosystem Functions in Agricultural Streams of Three Biogeographical Regions in Europe" (2007) 382 The Science of the Total Environment 272; E Malaj et al, "Organic Chemicals Jeopardize the Health of Freshwater Ecosystems on the Continental Scale" (2014) 111 Proceedings of the National Academy of Sciences 9549; Liess and Ohe, supra, note 2; Beketov et al, supra, note 2.

32 J Plötner and J Matschke, "Acute and Sublethal Toxicity and Indirect Effects of Glyphosate and Its Formulations on Amphibians - A Review" (2012) 19 Zeitschrift Feldherpetologie 10; Relyea, "The Impact of Insecticides and Herbicides on the Biodiversity and Productivity of Aquatic Communities: Response", supra, note 25; Bundesanstalt für Naturschutz, "Auswirkungen von Glyphosat auf die Biodiversität" 13.

33 MS Balbuena et al, "Effects of Sublethal Doses of Glyphosate on Honeybee Navigation" (2015) 218 Journal of Experimental Biology 2799; MA Benamú, MI Schneider and NE Sánchez, "Effects of the Herbicide Glyphosate on Biological Attributes of Alpaida veniliae (Araneae, Araneidae), in Laboratory" (2010) 78 Chemosphere 871; MI Schneider et al, "Impact of Glyphosate on the Development, Fertility and Demography of Chrysoperla externa (Neuroptera: Chrysopidae): Ecological Approach" (2009) 76 Chemosphere 1451.

34 Bundesanstalt für Naturschutz, supra, note 32.

35 ibid. 
through: (1) direct toxic effects on non-target organisms; or (2) indirect effects on nontarget organisms. Direct toxic effects on non-target organisms are further subdivided into lethal and sub-lethal effects. Because of its chemical structure, from a purely theoretical analysis, it is widely assumed - correctly or not - that there are no direct effects of glyphosate on insects. Most biologists indicate that glyphosate's principal effects on insects result from harms to food webs that negatively impact the agricultural landscape and organisms. Thus, the German environmental ministry claims: "The use of broad spectrum herbicides such as glyphosate does not kill insects directly". ${ }^{36}$ The tricky part, however, is that the complicated indirect effects (as well as a range of conceptions of what counts as an indirect effect) actually do end up harming a variety of insects. ${ }^{37}$ The complexity of these effects is exploited by various actors to give vastly contrastive interpretations about the scale of the problem and the chemical's safety. The impact of glyphosate in water includes indirect harms to the insects and other lifeforms that inhabit it.

The most influential EU agency in this sphere is EFSA, which advises the Commission and has been at the centre of European glyphosate regulation through its risk assessment. ${ }^{38}$ EFSA notes that glyphosate acts as a broad-spectrum herbicide against all plants that are not protected by a specific genetic modification. The active ingredient stops the synthesis of certain amino acids that are essential for plant growth, leading to plant death. As an individual substance, glyphosate has a relatively low (eg chronic) toxicity compared to the worst agrochemicals historically - such as DDT - and appears much less immediately toxic; here, most ecotoxicologists and regulatory agencies agree.

Yet, as debated as the dysergistic toxicity of glyphosate plus its adjuvants has been for EFSA, less recognised or accounted for in toxicity regulation has been glyphosate's indirect effects on aquatic ecosystems. Because of the complexities of chemically dependent agricultural production systems and land use configurations impacting biodiversity, these often delayed or indirect processes have received less focus in chemical regulation. Agrochemical use is linked to reduced biodiversity through cascading ecosystem effects involving freshwater contamination, even if biodiversity loss may not be directly caused by it. "39 "Indirect effects" are usually described as the deterioration of plant and microbial life in agricultural landscapes; these effects are especially demonstrable on food webs. The influential 2019 Leopoldina report describes how, at the community level, herbicides doing damage to plants will have indirect food chain effects (glyphosate was explicitly named), and that these

\footnotetext{
36 Bundesministerium für Umwelt, Naturschutz und nukleare Sicherheit, "Was Ist Der Zusammenhang Zwischen Glyphosat und Insektensterben? I FAQ I BMU" < https://www.bmu.de/faq/was-ist-der-zusammenhang-zwischenglyphosat-und-insektensterben/> (last accessed 13 March 2020).

37 Eg, EVS Motta, K Raymann and NA Moran, "Glyphosate Perturbs the Gut Microbiota of Honey Bees" (2018) 115 Proceedings of the National Academy of Sciences 10305.

38 European Food Safety Authority, EFSA Explains Risk Assessment: Glyphosate (Parma, EFSA 2015) <http:// bookshop.europa.eu/uri?target=EUB:NOTICE:TM0415780:EN:HTML> (last accessed 12 March 2020).

39 Battaglin et al, supra, note 3; MS Vera et al, "New Evidences of Roundup® (Glyphosate Formulation) Impact on the Periphyton Community and the Water Quality of Freshwater Ecosystems" (2010) 19 Ecotoxicology 710; OK Borggaard and AL Gimsing, "Fate of Glyphosate in Soil and the Possibility of Leaching to Ground and Surface Waters: A Review" (2008) 64 Pest Management Science 441.
} 
processes have not been adequately accounted for in regulatory approval procedures (which focus on individual populations instead). ${ }^{40}$ Yet different disciplines and even different schools of thought within ecology disagree over the implications of "indirect" ecological effects. We designate "indirect effects" here to encompass the notion of indirect toxicological and ecological effects that can result from dysergistic amplification through other effluents and exposures stemming from industrialised agricultural production. Concretely, glyphosate enables and furthers the usage of vast monocultural landscapes (and hence, inter alia, limits crop rotation and locks in specific economics activities and food supply and land use arrangements). These indirect effects from use on production processes have knock-on effects that potentiate the actual direct biochemical risks of glyphosate and its adjuvants. As the most used herbicide worldwide (total historical use globally until 2016 amounts to 6.1 billion kilograms), ${ }^{41}$ whatever glyphosate's determined indirect effects, by virtue of the volume of use, these indirect effects will likely be more pronounced and varied. The paradox that glyphosate is relatively inexpensive and putatively efficacious for crop protection in the dominant high-input agrichemical industrial food production model may render regulators reluctant to directly confront the other costs of the chemical, such as the ecological ones. ${ }^{42}$

Worldwide, glyphosate enables genetically modified (GM) plants to be bred to be glyphosate-resistant. In Europe, glyphosate is authorised for specific uses (in the context of GM crops being generally prohibited). In the case of Germany, for example, it is used mostly for stubble management (with uses such as siccation - the pre-harvest application of pesticides to quicken the crop-drying process - increasingly being outlawed), while in select countries glyphosate is also approved for aquatic or semi-aquatic use. Broad agreement among the regulators involved in the two authorisation procedures at the European and national levels exists that glyphosate and glyphosate-based products themselves do not constitute major problems for biodiversity in Europe according to the metrics of the prevailing risk assessment system.

The seeming consensus on the lack of direct biodiversity problems of glyphosate is surprising, as for some pesticides, such as neonicotinoids, achieving scientific consensus regarding clearly demonstrated biodiversity impacts has been swift and effective for establishing the case for regulatory action. ${ }^{43}$ Yet for glyphosate, scientists and policymakers by and large have agreed that, for the purposes of the European authorisation processes, glyphosate should not be outlawed for ecological reasons. It should be noted, however, that the risk assessment system unnecessarily confines itself to single-substance analysis only, as discussed below. Agencies such as Germany's BfN, for example, which are not directly involved in the authorisation

\footnotetext{
40 A Schäffer et al, Der Stumme Frühling: Zur Notwendigkeit Eines Umweltverträglichen Pflanzenschutzes (Halle, Deutsche Akademie der Naturforscher Leopoldina eV - Nationale Akademie der Wissenschaften 2018).

41 See CM Benbrook, "Trends in Glyphosate Herbicide Use in the United States and Globally" (2016) 28(1) Environmental Sciences Europe 3.

42 Duke and Powles, supra, note 21.

43 BA Woodcock et al, "Impacts of Neonicotinoid Use on Long-Term Population Changes in Wild Bees in England" (2016) 7 Nature Communications 12459; M Rundlöf et al, "Seed Coating with a Neonicotinoid Insecticide Negatively Affects Wild Bees" (2015) 521 Nature 77; SC Kessler et al, "Bees Prefer Foods Containing Neonicotinoid Pesticides" (2015) 521 Nature 74
} 
system or risk assessment, have been much more critical of the biodiversity effects of glyphosate than the responsible regulatory agencies involved in the two-tier authorisation system, claiming that "the current state of science indicates that indirect effects of glyphosate or glyphosate-containing herbicides on non-target species in particular pose a high risk to biodiversity" ${ }^{44}$ Such statements contrast with industry assessments that argue that a ban on glyphosate is associated with increased environmental pressures from agriculture due to compensating by deploying more intensive agribusiness practices requiring higher volumes of potentially more toxic chemicals, leading to worse biodiversity outcomes. ${ }^{45}$

Such outsider opinions to established regulatory systems circumvent entrenched risk assessment paradigms and criticise regulatory agencies for regulating only individual chemicals in isolation rather than the admixtures used in practice. ${ }^{46}$ Likewise, cocktail effects and multiple stressors are at the same time observed as being understudied ${ }^{47}$ and are thought to be under-regulated, as certain substances are potentiated by others (eg atrazine and glyphosate amplifying each other's toxicological affects). ${ }^{48}$ One study looking at how sunlight can potentiate the toxicity of certain pesticides assaying cell micronuclei found pesticides, including glyphosate, to be twenty-fold more toxic when mixed, and the mixture became 100 times more toxic after light irradiation due to oxidative stress. ${ }^{49}$ Prevailing environmental risk assessment methods are widely acknowledged to be deficient for accurately measuring the unintended cocktail effects of pesticides. ${ }^{50}$ It is no simple matter, however, to resolve this issue: complications regarding risk assessments of pesticides are controversial and receive a high level of scrutiny. ${ }^{51}$

In addition to the discrepancy of regulatory assessments focusing on single isolated chemicals and the cocktail mixtures of chemicals actually applied in situ are the problems of so-called "higher tiered" risk assessments. Higher-tiered issues coalesce around the deficiency of pesticide risk assessments based on models of predicted exposure concentration (PEC) in the environment as required within legal bounds of certain concentrations in order to be designated safe for non-target organisms in EU as well as US risk assessment. In this system, the regulatory acceptable concentration (RAC) is the cornerstone of the risk assessment process. This threshold has been

44 Bundesanstalt für Naturschutz, supra, note 32.

45 Bayer, supra, note 21.

46 W Wagner, "Using Competition-Based Regulation to Bridge the Toxics Data Gap" (2008) 83 Indiana Law Journal 631.

47 Beketov et al, supra, note 2, "Ecosystem effects of chronic low-level exposures to pesticide mixtures are uncertain".

48 Vera et al, supra, note 39; A Roustan et al, "Genotoxicity of Mixtures of Glyphosate and Atrazine and Their Environmental Transformation Products before and after Photoactivation" (2014) 108 Chemosphere 93.

49 Roustan, supra, note 48.

$50 \mathrm{KC}$ dos Santos and CBR Martinez, "Genotoxic and Biochemical Effects of Atrazine and Roundup®, Alone and in Combination, on the Asian Clam Corbicula Fluminea" (2014) 100 Ecotoxicology and Environmental Safety 7; Y Kim et al, "Mixtures of Glyphosate and Surfactant TN20 Accelerate Cell Death via Mitochondrial Damage-Induced Apoptosis and Necrosis" (2013) 27 Toxicology In Vitro 191; C Heu et al, "A Step Further toward GlyphosateInduced Epidermal Cell Death: Involvement of Mitochondrial and Oxidative Mechanisms" (2012) 34 Environmental Toxicology and Pharmacology 144.

51 CA Damalas and IG Eleftherohorinos, "Pesticide Exposure, Safety Issues, and Risk Assessment Indicators" (2011) 8 International Journal of Environmental Research and Public Health 1402. 
problematised as a "controlled experimental tiered risk assessment approach, giving results that are difficult to extrapolate to a real-world situation". ${ }^{2}$ Reliance on ecotoxicity data from "laboratory and semifield (so-called mesocosm) studies" 53 alone is particularly problematic, as safety concentrations are established through "[s]tandard toxicity tests, i.e., tests performed with single chemicals and single species under laboratory conditions without additional stressors". ${ }^{54}$ A Pesticides Action Network (PAN) report notes the following: "Microcosm and mesocosm systems are widely used in pesticide approvals; their attractiveness can easily be explained because the standards for aquatic toxicity can be made less strict [emphasis added] in numerous ways compared to the lower tier studies. This is partly due to the system itself (clean water, no pollution, variety of organisms) and statistical methods applied but also because uncertainty factors are lowered or not used anymore in higher tier". ${ }^{5}$

Such toxicity analyses are a far cry from the other threshold, which operationalises "[s]afety factors (also called assessment factors) that account for uncertainties in the extrapolation to real ecosystems". 56 This evident mismatch between results from field studies ${ }^{57}$ (showing that the "relationship between pesticide exposure and community composition is causal") and experimental tests relevant for regulation excludes the key ingredient for regulations: actual outcomes rather than theoretical safety. Apart from underspecified protection goals, Schäffer et al argue that there is no "scientifically validated prediction framework" that combines "ecological context, landscape context, farmer behaviour" and other non-laboratory aspects needed to predict exposure and effects. ${ }^{58}$ Instead, provisional authorisation solutions have been proposed (similar to suggestions to include post-monitoring of pesticide vigilance as guiding principles).

The relative problems with the tiered risk assessment system are less significant for unambiguously toxic pesticides where predicted exposure exceeds "safe concentrations", but they are greater for pesticides where the gap between predicted and actual exposure widens. Agrochemicals that are less predictable in terms of their field toxicity can nonetheless be authorised "if the producer can show through further data that its environmental and human health impacts are acceptable". 59 The virtue of tiered frameworks is that they allow for extending assessment to further ecological safety analysis encompassing more complex scenarios where "[h]igher tiers integrate processes and characteristics occurring in natural ecosystems, such as multi-species semi-field test systems in the EU, as well as reduction of exposure through mitigation measures in risk management". 60 These aggregating assessments can usefully be fed back into reassessing

\footnotetext{
52 MG Vijver et al, "Postregistration Monitoring of Pesticides Is Urgently Required to Protect Ecosystems" (2017) Environmental Toxicology and Chemistry Wiley Online Library <https://setac.onlinelibrary.wiley.com/doi/full/10. 1002/etc.3721> (last accessed 13 March 2020).

53 RB Schäfer et al, "Future Pesticide Risk Assessment: Narrowing the Gap between Intention and Reality" (2019) 31 Environmental Sciences Europe 21.

54 ibid.

55 Muilerman, supra, note $17,49$.

56 ibid.

57 Schäfer, supra, note 31.

58 Schäfer et al, supra, note 53 .

59 ibid.

60 ibid.
} 
risk at more core levels. Such analyses provide for water issues and ensuing biodiversity harms becoming more legible and weighty in risk assessments than they otherwise might.

Schäffer et al point out that the issue with this framework is that by default "authorization is given as long as the predicted exposure concentration (PEC) does not exceed the predicted no-effect concentration identified by single tiers, multiplied by the respective safety factor. Only substances that fail all tiers are not authorized". 61 The most likely result of the safety threshold system is a no-effect judgment, because the regulatory edifice is built on laboratory toxicity testing and the format of tiered studies with little initial input from field studies. Such systematic underestimations (or type II biases) can lead to "inaccurate predictions of both exposure and effects in tiered system". ${ }^{62}$ This critique by ecotoxicologists of the existing risk assessment framework is shared by other scientists critical of glyphosate's ecological harms. ${ }^{63}$ Likewise, the German Federal Environmental Agency (Umweltbundesamt, UBA) criticises tiered risk assessment as often counterproductive for ecosystems, unnecessarily expensive and too difficult to communicate to the public. ${ }^{64}$ The recent Leopoldina report entitled "The Silent Spring" also delineates problematic details of the tiered risk assessment as practised today, such as deliberately not double-checking pesticide effects that have been vetted at other levels. ${ }^{65}$ The very few experts on these issues are in consensus: "[C]ritical revisions of related pesticide regulations and effective mitigation measures are urgently needed to substantially reduce the environmental risks arising from agricultural insecticide use". 66

In recent months, the pan-European politicisation of glyphosate as a problematic chemical has brought the entire risk assessment framework under serious scrutiny. ${ }^{67}$ Nonetheless, possibly because there are only a handful of people who understand the intricacies of the issues at hand, or due to a lack of political interest groups advocating for the rights of aquatic ecosystems, the specific issue of harm to aquatic ecosystems as a result of omissions in the risk assessment framework has not been made.

Defenders of the status quo risk assessment procedures note that regulatory tools, especially the guidance recommendations used by EFSA, undergo continuous development, and already include indirect effects (albeit in the limited sense described above). New test and reference organisms can be specified and extended, and as climate conditions continue to change, updates to the pre-existing models can occur. Similarly, different models to calculate PECs are being constructed, with much effort being spent to coordinate such approaches across scientific and regulatory institutions. Even with these updates and addenda, however, the tiered framework

\footnotetext{
61 ibid.

62 ibid.

63 Robinson et al, supra, note 11.

64 T Frische et al, 5-Punkte-Programm für einen nachhaltigen Pflanzenschutz (Dessau-Roßlau, Umweltbundesamt 2016) < https://www.umweltbundesamt.de/publikationen/5-punkte-programm-fuer-einen-nachhaltigen-0> (last accessed 4 June 2020).

65 Schäffer et al, supra, note $40,18$.

66 Stehle and Schulz, supra, note 18.

67 G Bazzan and M Migliorati, "Expertise, Politics and Public Opinion at the Crossroads of the European Commission's Decision-Making: The Case of Glyphosate" (2020) 2 International Review of Public Policy <http:// journals.openedition.org/irpp/849> (last accessed 18 May 2020).
} 
does not consider aggregate pressure, and it uses laboratory tests as approximations of real-world effects. For these reasons, the tiering system prevents ecosystem effects from being material in decision-making by isolating pertinent cross-effect observations through unnecessarily complex regulatory stringencies that are inscrutable to most involved parties. Glyphosate in its pure form (which occurs only in the laboratory) is paradoxically then assessed as low toxicity and perfectly "adapted" for regulatory systems unwilling or unable to capture real-world indirect effects - especially in aquatic systems.

\section{Much MORE THAN GLYPHOSATE (OR HOW RISK ASSESSMENT MARGINALISES THE ASSESSMENT OF ENVIRONMENTAL RISK)}

Bernhard Url, EFSA's executive director, responded in a recent interview with news media Euractiv that he views the conflation of science and politics in the glyphosate saga as "unreasonable":

Glyphosate has become the symbol of much more: it's no longer about a herbicide, but about the way we do agriculture in Europe, the loss of insects and pollinators, the globalisation of trade, biodiversity ...

This can only be dealt with proper communication but also with a reasonable distinction between what is policy and what is science. To give you an example, people were surprised when they found glyphosate in the urine of their children. But this is a policy question: if we use glyphosate, we will find it, because analytical methods are so sensitive nowadays that basically everything can be found.

If you don't want to find traces of glyphosate in beer or in spaghetti, then you have to talk about its use and not about its safety. All the traces have been found present no safety concerns and all other regulators in the world have said it is safe if it is used properly. But it does not mean that it has to be used.

What I hope for the next glyphosate reauthorisation is that there's also an assessment on what would it mean, if glyphosate or herbicides are not used anymore for biodiversity, water, farmers income, food prices, availability of foods and so on. This was what we missed in the previous glyphosate discussion. ${ }^{68}$

Url is correct in assessing that glyphosate has ballooned into a banner representing a host of structural issues. Arguably, the glyphosate case is not just a symbol of "much more", but an epiphenomenon of "much more"; it reflects that current risk regulation compartmentalises risk diagnoses in such a way that critical questions are eluded or "back-staged". ${ }^{69}$ In fact, glyphosate is always excessive in its significance; there is no

68 G Fortuna, "EFSA Boss: Next Time We Should Also Assess Consequences without Glyphosate" (www.euractiv. com, 21 May 2019) <https://www.euractiv.com/section/agriculture-food/interview/efsa-boss-next-time-we-shouldalso-assess-consequences-without-glyphosate/> (last accessed 13 March 2020). Emphasis added.

69 A Arcuri, "Glyphosate" in J Hohmann and D Joyce (eds), International Law's Objects (Oxford, Oxford University Press 2018) pp 234-46; see pp 242-43. 
such a thing as raw glyphosate in its actual use. Glyphosate as actually applied in any of its over 700 commercial formulations used in the physical environment is blended with an array of compounds (such as adjuvants and co-formulants) and typically receives little scrutiny by domestic regulators, as mentioned above. ${ }^{70}$ The chemical imaginary of glyphosate as a pure product, divorced from its adjuvants and co-formulants, does not exist, and, as has been argued, should not be treated as if it did for regulatory purposes. Yet, risk assessments code current law to individually assessed chemicals without assessing them in the light of real-world chemistry, in which they are blended together. Treating chemicals separately from a regulatory perspective, instead of informing regulation by the science of chemistry and chemical interactions, is an expedient legal artifice. At this point, it is worth recalling that the European legal framework establishes a two-track system for the approval of pesticides: the active substance, in this case glyphosate, is assessed and approved at the EU level, whereas the different formulations are approved at the level of individual Member States and further circulated in the internal markets through mutual recognition. ${ }^{71}$

The EU Parliament, in its 2018 Report on the Union's authorisation procedure for pesticides, has noted the difficulties of approval procedures at the national level as follows: “. . . understaffing and/or underfunding may result in over-reliance on the assessment conducted for the approval of the active substances in the context of decisions for plant protection products". ${ }^{72}$ Assessing the numerous pesticide products containing glyphosate with the same degree of granularity as for active substances ( 700 commercial formulations versus a single active substance) could in fact prove to be a daunting task and disrupt industrial agriculture. In this context, scholars have criticised the fact that "[p]esticide co-formulants considered to be inert are generally exempt from the requirement for establishing a tolerance limit, and for this reason, end-use commercial pesticide formulations escape from being subjected to chronic toxicity testing, despite the fact that the vast majority that have been tested are actually more toxic than the declared active ingredients alone". ${ }^{73}$

In this respect, it warrants note that in the process for the 2017 re-authorisation of glyphosate, the EU Commission took the unprecedented decision to propose a ban on one of the main co-formulants used in glyphosate-based pesticides: POEA. Yet, POEA continues to be used in other pesticides (without glyphosate) and can be bought in the market "as a separate adjuvant mixture (product name Regain,

\footnotetext{
70 K Nagy et al, "Systematic Review of Comparative Studies Assessing the Toxicity of Pesticide Active Ingredients and Their Product Formulations" (2020) 181 Environmental Research 108926; J Niedobová et al, "Synergistic Effects of Glyphosate Formulation Herbicide and Tank-Mixing Adjuvants on Pardosa Spiders" (2019) 249 Environmental Pollution 338.

71 See Art 41 Regulation (EC) No 1107/2009 of the European Parliament and of the Council of 21 October 2009 concerning the placing of plant protection products on the market and repealing Council Directives 79/117/EEC and 91/414 (OJ 2009 L 309, p 1).

72 European Parliament, Report on the Union's authorisation procedure for pesticides (2018/2153(INI)), A8-0475/ 2018, 18.12.2018., at BW, p 14.

73 R Mesnage et al "Insight into the confusion over surfactant co-formulants in glyphosate-based herbicides" (2019) 128 Food and Chemical Toxicology 137, 138. See also R Mesnage et al, "Potential toxic effects of glyphosate and its commercial formulations below regulatory limits" (2015) 84 Food and Chemical Toxicology 133.
} 
authorization 9300433) to mix with a glyphosate formulation in the spray tank". ${ }^{74}$ The fact that a specific co-formulant found to be dangerous at the EU level continues to be used in non-glyphosate-based pesticides is further evidence of how formulations containing toxic "ingredients" could more easily go undetected at the domestic level.

Against this background, one can agree with Dr Url in emphasising the importance of distinguishing "what is policy and what is science". The choice to assess only the active substance (glyphosate) at the EU level cannot be separated from political choices. More generally, risk assessment is a practice that is deeply embedded in law. As one participant to an EFSA Management Board meeting said: "[I]t should be emphasized also that it is legally-binding evidence-based risk assessment [that EFSA is following] . . . that EFSA, by its mandate, will not take into consideration all available information for legal reasons". ${ }^{75}$ The difficulty with agencies such as EFSA making risk assessments on chemicals such as glyphosate is that often such assessments become interpreted by the general public, as well as scientists, as scientific findings or official consensus rather than as hybrid practices rooted in science as well as in policy processes. ${ }^{76}$

The decision to structure risk assessment around the identification and measurement of certain risks by a single isolated substance is another notable political choice. The main health lens applied so far, for example, has been on carcinogenic risk. This is arguably because the EU Regulation establishes that carcinogenicity is a cut-off criterion to decide when a substance should be banned. ${ }^{77}$ Much less attention is paid, however, to environmental risks, and by extension the downstream environmental health threats, despite this regulation equally protecting the environment. ${ }^{78}$ The case of water is a representative example. A report by the NGO Pesticide Action Network alleges several instances of weakened protective standards throughout the EU regulatory framework through controversial risk assessment methodologies, highlighting specifically the treatment of potentially harmful metabolites in ground water as "non-relevant" 79 Generally, it is the description of data requirements in the sections on ecotoxicology and environmental fate and behaviour that is determinative.

When the risk to aquatic environments is considered, the EFSA report lacks clarity. The report's conclusions mention that "[g]lyphosate and AMPA have been detected in Europe above the parametric limit of $0.1 \mu \mathrm{g} / \mathrm{L}$ in a number of instances. Detailed groundwater monitoring studies demonstrating that glyphosate exceeded the limit of $0.1 \mu \mathrm{g} / \mathrm{L}$ were available from Italy, Germany, the Netherlands, Sweden, France and

\footnotetext{
74 See Pest Committee Meeting of 28 June 2018 EU Authorisation Procedure for Pesticides - Authorisation of Plant Protection Products by Member States. Preparatory Questions, Answers Given by Mr Robin Mesnage, at p 4.

75 EFSA, 67th Management Board Meeting 3 December 2015, Discussion EFSA progress report, available at $<$ http:// www.efsa.europa.eu/en/events/event/151203\#playaudio> (last accessed 28 June 2020) at 51 minutes (emphasis added).

76 S Hartley, "Policy Masquerading as Science: An Examination of Non-State Actor Involvement in European Risk Assessment Policy for Genetically Modified Animals" (2016) 23 Journal of European Public Policy 276; Demortain, supra, note 12; Jasanoff, "Science, Politics, and the Renegotiation of Expertise at EPA", supra, note 10; Funtowicz and Ravetz, supra, note 10 .

77 See Art 4 and 3.6.2 to 3.6.4 and 3.7 of Annex II, Regulation 1107/2009, supra, note 71 .

78 See Art 4 (2)(a) and (b), Regulation 1107/2009, supra, note 71, where it is provided that plant protection products (a) "shall not have any harmful effects ... on groundwater" and "(b) they shall not have any unacceptable effect on the environment".

79 Muilerman, supra, note 17.
} 
Spain". The assessors explain that these contaminations may be due to "misuse" of the product and that drinking water can be treated using chlorinating procedures. ${ }^{80}$ But even if "misuse" would be the primary case of the violation of parametric limits, should such "misuse" not be considered as part of the embodied risk?

Interestingly, in different contexts, other EU legal representatives consider the use or misuse of potentially toxic products as part of risk and hence of "risk assessment". This has been an issue in the Hormones dispute between the EU and the USA. The World Trade Organization (WTO) Appellate Body has concluded that "abuse" or "misuse" of potentially toxic products can be considered as part of risk assessment. ${ }^{81}$ In this context, the EU has tried to defend its precautionary policies (eg vis-à-vis the use of hormones in food chains for growth-promotion purposes), which, to be fully realised, may need a more holistic conceptualisation of risk assessment. It could be argued that by considering real harms as products of misuse rather than design or inaccurate modelling, both companies and regulatory agencies, across industries, effectively externalise actual risk. ${ }^{82}$

As mentioned above, another major limit to the type of risk assessment used for regulatory purposes is that it does not examine chemical mixtures and their synergistic (dysergistic) impacts. ${ }^{83}$ Yet, the aquatic environment is exposed to these mixtures together rather than single substances sequentially. Risk assessment practices also fail to retrospectively look at the data produced through environmental monitoring that examines the manifold ways through which chemicals are transformed by the substrate through which they travel and react. ${ }^{84}$ In this respect, the European Court of Auditors has issued a Special Report that criticises - among others - the deficient status of the environmental monitoring of pesticides. ${ }^{85}$

To fully understand how environmental risk is further side-lined in contemporary practices of risk assessment, we need to take a step back and look at how pesticides

\footnotetext{
80 See European Food Safety Authority, "Conclusion on the Peer Review of the Pesticide Risk Assessment of the Active Substance Glyphosate” (2015) 13 EFSA Journal 4302; Muilerman, supra, note 17, 17.

81 The question of whether abuse of misuse of potentially toxic substances should be part of a risk assessment has been addressed by the WTO Court, when considering the risks of hormones used for growth promotion. In that context, the Appellate Body found that "the abuse or misuse in the administration of oestradiol-17 $\beta$ has a bearing on the particular risks being assessed by the European Communities". See Appellate Body Report, United States - Continued Suspension of Obligations in the EC - Hormones Dispute, WT/DS320/AB/R, adopted 14 November 2008 (US - Continued Suspension).

82 L Dorfman et al, "Soda and Tobacco Industry Corporate Social Responsibility Campaigns: How Do They Compare?" (2012) 9 PLoS Medicine e1001241; J Elias, YH Hendlin and PM Ling, "Public versus Internal Conceptions of Addiction: An Analysis of Internal Philip Morris Documents" (2018) 15 PLoS Medicine e1002562; $\mathrm{H}$ Vainio, "Public Health and Evidence-Informed Policy-Making: The Case of a Commonly Used Herbicide" (2020) 46 Scandinavian Journal of Work, Environment \& Health 105; PA McDaniel, EA Lown and RE Malone, “"'It Doesn't Seem to Make Sense for a Company That Sells Cigarettes to Help Smokers Stop Using Them”: A Case Study of Philip Morris's Involvement in Smoking Cessation" (2017) 12 PLoS ONE e0183961; EA Smith and TE Novotny, "Whose Butt Is It? Tobacco Industry Research about Smokers and Cigarette Butt Waste" (2011) 20(Suppl. 1) Tobacco Control i2.

83 European Commission and Directorate General for Health \& Consumers, Toxicity and Assessment of Chemical Mixtures (Brussels, European Commission 2012).

84 European Commission and Directorate General for Health \& Consumers, Addressing the New Challenges for Risk Assessment (Brussels, European Commission 2013) < http://bookshop.europa.eu/uri?target=eub:notice:ndaz13002:en: html > (last accessed 11 March 2020).

85 European Court of Auditors, "Sustainable use of plant protection products: limited progress in measuring and reducing risks", Special Report 5 February 2020, paras 44-52.
} 
are regulated in Europe through Regulation 1107/2009 concerning the placing of PPPs on the market and Directive 2009/128/EC on the sustainable use of pesticides. ${ }^{86}$ The European legal framework can be seen as a dual system. As briefly mentioned above, on the one hand, active substances (such as glyphosate) are to be assessed and approved by EU institutions; on the other hand, the commercial products to be placed on the market (including co-formulants) are approved by national authorities and can further circulate in Europe by virtue of mutual recognition. Next to the authorisation process, this dual system is reproduced in how issues of sustainability are addressed. In this context, Directive 2009/128, which has the general goal of achieving "a sustainable use of pesticides by reducing the risks and impacts [not necessarily the amount] of pesticide [like glyphosate] use on human health and the environment and promoting the use of integrated pest management and of alternative approaches or techniques such as non-chemical alternatives to pesticides" (see Article 1, Directive 2009/128), establishes only few specific obligations on Member States (eg prohibition of aerial spraying, per Article 9). For the rest, it delegates to the Member States the enactment of specific measures through the adoption of National Action Plans (NAPs; see Article 4, Directive 2009/128). As a result, the question of whether the use of pesticides like RoundUp® is reduced and/or used more sustainably depends on the measures adopted by individual Member States. In this context, it is worth mentioning that reduction targets are absent from virtually all NAPs (the main exception being France). ${ }^{87}$

NAPs have been widely criticised by environmental groups. Looking at the Directive itself, it becomes clear that, at the heart of the EU Directive, a vague political compromise ends up eliding concrete policy objectives: the Directive leaves slack in interpreting whether the absolute quantities of pesticides should be reduced, or "merely" the associated risk of pesticide use: “. . . risk reduction or use targets shall be set at times and targets for the restriction of use, in particular where the restriction of use is an appropriate instrument to achieve risk reduction in relation to the priority topics referred to in Article 15(2)(c)". According to EU law, NAPs require stakeholder participation and, in principle, the possibility to publicly scrutinise pesticide-related plans. The inadequacy of these plans has been nowhere as clear as in Germany, where, in 2011, stakeholders that aligned with environmental interests left the NAP in protest (surprisingly, this included the commercial German association of energy and water industries, BDEW). NGOs report that a lack of transparency and a dubious selection of indicators were the reasons for their withdrawal from the NAP, noting that the ministry-led process would - in the end - strengthen the current system of agricultural use of chemical PPPs rather than reduce dependency on agrochemicals. ${ }^{88}$

\footnotetext{
86 See Regulation (EC) No 1107/2009, supra, note 71, and Report from the Commission to the European Parliament and the Council on Member State National Action Plans and on progress in the implementation of Directive 2009/128/ $\mathrm{EC}$ on the sustainable use of pesticides 10.10.2017 $\operatorname{COM}(2017) 587$ final, at 1.

87 See Report from the Commission to the European Parliament and the Council, supra, note 86, 5.

88 For a detailed statement of German environmental NGOs like PAN, NABU, BUND and Greenpeace, see <http:// www.pan-germany.org/download/Umweltverbaende_Stellungnahme_zum\%20_NAP_Entwurf_vom_270912.pdf> (last accessed 1 June 2020).
} 
In this way, the NAPs demonstrate power imbalances in participatory processes of environmental entrenched interests that contradict those of protectors of aquatic ecosystem health, and instead do not address issues such as the excessive use of glyphosate. In this context, PAN criticises the Dutch NAP as an example of private actors drawing up guidelines for agricultural application without broad stakeholder participation. ${ }^{89}$ The binding nature of the NAPs varies from country to country, but is extremely weak overall. In Denmark, for example, the ban of chemical pesticides in certain areas for urban drinking water falls into abstraction due to the lack of concretisation in determining an "overall pesticide load indicator". In addition to countless unambitious declarations of intent, as in Germany or Poland, there are also processes of silent adoption of binding targets, as in the Netherlands in terms of plant protection plans, where plant protection monitors have been suddenly introduced.

In Germany, the coalition government announced a national insect protection programme that calls for the reduction of pesticides, especially glyphosate, with a specific stipulation of phasing out the herbicide completely by $2023 .{ }^{90}$ Polls in Germany suggested that more than seven out of ten people favour a ban on the substance, ${ }^{91}$ which was cited to be a factor in the agreement of both agricultural and environmental ministries to this phase-out. ${ }^{92}$ But Germany's responsible agency BVL authorised its use until 15 December 2020 for another year, without any changes to application rules, or even regulation of private usage, or any type of minimisation/ reduction strategy. ${ }^{93}$ And the Glyphosate Renewal Group - a group of agrochemical producers - has already submitted applications for renewal of the substance after $2023 .{ }^{94}$ The battle around glyphosate was the catalyst for the inception of the PEST Committee of the European Parliament in 2018.95

Regrettably, beyond the obligation of developing NAPs, the question of how Member States can and should assess the risks of pesticides remains elusive. As mentioned above,

89 PAN Europe, “Monitoring EU SUD Compliance: PAN's Suggestions for Better Future Auditing and Implementation" (2018) <https://www.pan-europe.info/resources/briefings/2018/10/monitoring-eu-sud-compliancepan\%E2\%80\%99s-suggestions-better-future-auditing > (last accessed 13 March 2020).

90 "Deutschland will Glyphosat bis Ende 2023 verbieten" (DER STANDARD) <https://www.derstandard.de/story/ 2000108231583/deutschland-will-glyphosat-bis-ende-2023-verbieten> (last accessed 14 March 2020); J Salz, "Warum Glyphosat, wenn auch heißes Wasser hilft?" (www.euractiv.de, 1 October 2019) <https://www.euractiv.de/section/ landwirtschaft-und-ernahrung/news/warum-glyphosat-wenn-auch-heisses-wasser-hilft/> (last accessed 14 March 2020).

91 A Neslen, "Two-Thirds of Europeans Support Ban on Glyphosate - Poll" (The Guardian, 11 April 2016) <https:// www.theguardian.com/environment/2016/apr/11/two-thirds-of-europeans-support-ban-on-glyphosate-says-yougovpoll> (last accessed 14 March 2020); INSA-Consulere GmbH, "Online Poll in Germany, France, Italy, Greece and Portugal" (2017) EU Glyphosate Poll <https://s3.amazonaws.com/s3.sumofus.org/images/Summary_results_glyphosate_ INSA_Oct_2017.pdf $>$ (last accessed 14 March 2020).

92 F Poetschke, "Minister Schulze Presents Plan for Glyphosate Phase-Out" (Umweltbundesamt, 9 November 2018) $<$ https://www.umweltbundesamt.de/en/press/pressinformation/minister-schulze-presents-plan-for-glyphosate-phase > (last accessed 14 March 2020).

93 Bundesamt für Verbraucherschutz und Lebensmittelsicherheit, "BVL - Fachmeldungen - Beschluss Des OVG Lüneburg: Rechtsmittel Gegen Verkürztes Zulassungsende Haben Aufschiebende Wirkung” (10 January 2020) $<$ https://www.bvl.bund.de/SharedDocs/Fachmeldungen/04_pflanzenschutzmittel/2020/

2020_01_23_Fa_Rechtsmittel_verkuerztes_Zulassungsende.html> (last accessed 14 March 2020).

94 "Glyphosate Renewal Group" (2020) <https://glyphosate.eu/> (last accessed 14 March 2020).

95 B Chatain, "Pesticides: Parliament to Set up Special Committee I News I European Parliament" (18 January 2018) $<$ https://www.europarl.europa.eu/news/en/press-room/20180118IPR92014/pesticides-parliament-to-set-up-specialcommittee $>$ (last accessed 14 March 2020). 
the Directive itself remains ambiguous as to the necessity (if not the urgency) of addressing the absolute quantities of pesticides discharged in the environment. In the Anthropocene, quantity is crucial to safety. But in a market-driven society, decreasing the quantity of agricultural inputs results in a net loss of income for the supplying manufactures. In this sense, it is remarkable how the regulatory framework marginalises questions of quantity. The fact that glyphosate is the most widely used active substance in pesticides worldwide is masterfully eclipsed by elusive NAPs. The words of Dr Url, which dissociate safety from use, may then reflect the resistance of a regulatory system that tends to privilege the protection of capital over the protection of the environment. At the very least, methodological assumptions baked into the system bias risk assessments towards the assumption of non-toxicity for all of the configurations of toxicity that are not known.

The case of water is exemplary in displaying how this disassociation seems to underpin the current EU legal framework, which marginalises sound appraisal and management of environmental risks. On the one hand, the legal framework recognises the importance of water; for example, Paragraph 15 of the Preamble of Directive 2009/128 explicitly refers to the fact that the "aquatic environment is especially sensitive to pesticides", and that "[i]t is ... necessary for particular attention to be paid to avoiding pollution of surface water and groundwater by taking appropriate measures, such as the establishment of buffer and safeguard zones or planting hedges along surface waters to reduce exposure of waterbodies to spray drift, drain flow and run-off". Moreover, according to Article 11, Member States shall establish specific measures to protect the aquatic environment and drinking water. On the other hand, the legal framework fails to establish the institutions to systematically collect information and monitor the effects of pesticides on aquatic environments and to protect the aquatic environment in effective ways. ${ }^{96}$ Numerous reasons contribute to the undercutting of these principles, and critical NGOs admonish that crucial information is overlooked, hidden in guidance documents or circumvented through undetected non-compliance with such documents, with a further issue being the political process surrounding the nomination of experts to relevant committees. ${ }^{97}$

In short, the legal architecture by which most attention is directed towards assessing the carcinogenic risk of the active substance diverts attention away from other important risks deserving of consideration, such as the risk to surface water and ground water. Despite the acknowledgment in the legal text that the (aquatic) environment should be protected (eg Article 4 Regulation 1107/2009 and Paragraph 15 of the Preamble of Directive 2009/128), the legal framework lacks strong and well-coordinated provisions to address this issue. This is not only evidenced by the weak NAPs of individual Member States, but also by the proven pollution of watercourses by glyphosate and the absence of (planned) corrective measures. ${ }^{98}$ Regrettably, the concrete rules relating to the protection of surface and ground waters remain aspirational at best.

\footnotetext{
96 In this respect, see also the Report from the Commission to the European Parliament and the Council, supra, note 86, where it states: "Member States have taken a range of measures to protect the aquatic environment from pesticide use, but in the absence of measurable targets in most national action plans it is difficult to assess the progress achieved" at 10 . 97 Muilerman, supra, note 17; Robinson et al, supra, note 11.

98 There is much evidence of contamination of water by glyphosate, as reported by EFSA. For additional evidence, see Paris, supra, note 23.
} 


\section{Discussion}

Let us return once again to the words of Bernd Url when he writes: "What I hope for the next glyphosate reauthorisation is that there's also an assessment on what would it mean, if glyphosate or herbicides are not used anymore for biodiversity, water, farmers [sic] income, food prices, availability of foods and so on". 99 This statement invites consideration of broader questions; yet, it conflates a number of key socio-political and scientific questions and, above all, implicitly forecloses the discussion of a plurality of scenarios. First, the statement suggests that the only choice we have is glyphosate/herbicide versus a fully pesticide-free world with the assumed knock-on hardships that would ensure. But, what about a significant reduction of the use of pesticides, or the adoption of biocompatible agrichemicals? Harm reduction in pesticide use is sometimes hyperbolically taken as an extreme abolitionism, rather than an admission that there is both a problem of chemical overuse in food production (with the documented consequences) and that realistic steps can be taken now to reduce the harms. The current legal system, with its split between a singlesubstance authorisation system and weak NAPs, seems oblivious to the total amount of pesticides used. Given the above analysis regarding the negative effects of glyphosate (and pesticides more generally) on the environment, it is striking that legally so little is done to reduce the total quantities of pesticides used in agriculture. It seems as if prevailing regulation has proved too blunt an instrument to deal with the incremental reductions necessary that would effect immediate improvement in health, ecological effects and ground water, without substantially upsetting prevailing high-input agricultural practices. Indeed, this gap in the regulatory system may also be seen as halting innovation and providing perverse incentives to firms. This structural gap has also been identified as a weakness of the EU legal framework by the recent report of the European Court of Auditors and as a major obstacle for "reducing the risks of PPP use". ${ }^{100}$ One hopes that the new resolve by the EU to adopt pesticide reduction targets, matured within the context of the New Green Deal, will be followed by concrete and resolute action. ${ }^{101}$

Second, viewing the legal system as a site of knowledge production permits enquiring into the focus on risk assessment and the serious limits of such assessments as currently practiced for the authorisation of active substances regarding what knowledge is considered relevant in the regulatory process. Crucially, by focusing on the carcinogenic risk of the isolated substances to the exclusion of other demarcating lines or factors, knowledge on the effects of real-world chemical mixtures gets side-lined, as well as the effects of chemical cocktails on aquatic environments and life dwelling in affected habitats. Marginalising the effects of chemicals on non-human organism populations is the current default, but there is no inevitability that it must have become so, nor for it to continue. One may ask, then, whether the current configuration of risk assessment practices constitutes a particular manifestation of a "hegemonic

99 Fortuna, supra, note 68.

100 See supra, note 77.

101 ES Nicolás, "EU wants to halve use of pesticides by 2030" (EU Observer, 20 May 2020) <https://euobserver. com/green-deal/148434> (last accessed 28 June 2020). 
principle of selectivity". ${ }^{102}$ When we engage uncritically with the question Url poses, we risk being oblivious of key scientific insights as well as socio-political questions. Url's statement may also eclipse another larger question: is the current risk assessment preventing us from engaging in an open and much-needed conversation around which types of agricultural practices are desirable for the Anthropocene era? ${ }^{103}$

Political, sociocultural and most of all economic entrenchment of agrochemicals make it very hard to regulate against them. Once introduced for crop protection as modern and effective, other methods become negatively valanced as primitive or archaic, even when they are also (or even more) effective (with potentially fewer side effects). The status quo bias in favour of supporting existing chemical use requires re-examining the entire infrastructure that led to such defaults, including the path dependency of approving given chemicals such as glyphosate.

Rather than ignoring or avoiding confrontation with the messy business of risk regulation by assessing the "easiest" and most "contained" models, making interdisciplinary sense of the sheer number of interactions and impacts chemical mixtures have as they react with their chemical and biological environments of application should be the actual matter of concern for risk regulation, however challenging it may be in practice.

Part of the weakness of social and political power in determining top-down whether or not a given population chooses the risks of such exposures emerges from the "divide and conquer" public relations of chemical manufacturers. ${ }^{104}$ In many instances of agrochemical risk regulation and its framing by agrochemical companies, farmers and consumers are pitted against each other, when in fact farmers are normally much more exposed than those who eventually consume their products. ${ }^{105}$ Paradoxically, farmers lobbying against their own health interests and for the status quo of the extensive inputs they depend on from agrochemical manufacturers means that entrenchment of harmful pesticides is often enacted by frontline proxies like farmers, who are most likely to suffer the health consequences. The reasons for farmers viewing pesticide regulations as threats to their successful harvests, rather than aiming at protecting their health and offering them effective alternatives, ${ }^{106}$ is a complex and

\footnotetext{
102 The term "hegemonic principle of selectivity" has been used by R Wolff, "Efficiency: Whose Efficiency" (2002) 16(3) Post-Autistic Economics Review 1. Discussing the concept of efficiency in economic analysis, the author writes, "Usually, one principle of selectivity reigns hegemonic: one set of selected effects is deemed 'important' and worth counting while others are marginalized or ignored altogether".

103 It should be noted that both the UN Special Rapporteur on the right to food and the UN Special Rapporteur on the implications for human rights of the environmentally sound management and disposal of hazardous substances and wastes, in noting the adverse impact of pesticides on human rights, agree that it is necessary to address the questions of sustainable agricultural practices. In their 2017 Report, they write: "It is time to overturn the myth that pesticides are necessary to feed the world and create a global process to transition toward safer and healthier food and agricultural production". See Press release, "Pesticides are 'global human rights concern', say UN experts urging new treaty" <https://www.ohchr.org/EN/NewsEvents/Pages/DisplayNews.aspx?NewsID=21306> (last accessed 28 June 2020).

104 Wagner, supra, note 46.

105 JP Myers et al, "Concerns over Use of Glyphosate-Based Herbicides and Risks Associated with Exposures: A Consensus Statement” (2016) 15 Environmental Health 19.

106 C Badgley et al, "Organic Agriculture and the Global Food Supply" (2007) 22 Renewable Agriculture and Food Systems 86.
} 
motivated history ${ }^{107}$ that is beyond the scope of this paper. It is evident, nonetheless, that taking seriously the intersectional issues of soil fertility, waterway health and human well-being requires a wholesale restructuring of the rules of agriculture to prevent an artificially input-driven race to the bottom. ${ }^{108}$

There is also no reason to ignore important known information regarding the effects of chemicals on any sort of organism population or life system. The intricacies of the scientific findings on these topics call for creating enough regulatory space to assess and assimilate new data as they become known and to update regulation in more or less real time to encompass and encourage data that might require rearranging risk assessments and their accompanying policies. Wagner has suggested that one way to address the "toxics data gap" is to force chemical manufacturers to compete against each other in terms of risk reporting requirements, which would in turn "reposition" the role of regulatory agencies to harness the "expertise, information, and energies of manufacturers of safer products eager to put their competitors' more hazardous products out of business" to benefit those companies that would gain through marketing safer products. ${ }^{109}$ A similar approach has been instituted in the United Nations Global Compact (UNGC), which rewards companies with social license for their environmental and social reporting transparency. This voluntary mechanism creates the positive externality of data baselines for industries, even when only a few rival manufacturers choose to be transparent, as those participating companies set the bar for the rest of the industry. While the UNGC is not without its problems, this facet at least seems to answer Wagner's call for creating a "market competition between rival firms to produce relevant information about the toxicity of certain chemical products on the market". 110

True, reconfiguring risk regulation to take into account the full spectrum of environmental and human health harms will likely substantially reprioritise certain low-externality farming methods over the known harms of industrial agriculture. However, such disruptive regulation can also provide new economic niches for techniques and environmentally integrated companies working in regenerative agriculture. ${ }^{111}$ More publicly and environmentally orientated risk regulations do not condemn the economics of farming, but perhaps change the players. Ecologies of innovation stipulate that companies and social creativity do not occur in isolation, but rather in ecosystems with other stimulating and constraining factors that uniquely establish niches to develop new technologies or services - which always interface

107 D Fagin and M Lavelle, Toxic Deception: How the Chemical Industry Manipulates Science, Bends the Law and Endangers Your Health (Monroe, ME, Common Courage Press 2002); M Nestle and M Pollan, Food Politics: How the Food Industry Influences Nutrition and Health (Rev Exp edition, Berkeley, University of California Press 2013).

108 UNCTAD, "Wake Up Before It Is Too Late. Make Agriculture Truly Sustainable Now for Food Security and Changing Climate" (United Nations Conference on Trade and Development 2013).

109 Wagner, supra, note 46, 631.

110 idem.

111 E Toensmeier, The Carbon Farming Solution: A Global Toolkit of Perennial Crops and Regenerative Agriculture Practices for Climate Change Mitigation and Food Security (Hartford, VT, Chelsea Green Publishing 2016); S Sherwood and N Uphoff, "Soil Health: Research, Practice and Policy for a More Regenerative Agriculture" (2000) 15 Applied Soil Ecology 85; CE LaCanne and JG Lundgren, "Regenerative Agriculture: Merging Farming and Natural Resource Conservation Profitably" (2018) 6 PeerJ e4428. 
with and are enabled by the state, whether consciously or not. ${ }^{112}$ Disruptive regulation for the public's benefit can restore commons, help farmers move away from soil-depleting agricultural practices fed by monopolised commodity chains, offer consumers more choice and empower ecologically focused companies previously at a disadvantage under previous chemical regimes.

Without a firm commitment to reducing overall pesticide use, however, such policies can be complicated by the tensions that regulatory agencies face due to not wanting to ban chemicals such as glyphosate because such a vacuum might result in new replacement chemicals that are even more dangerous than existing ones. An example of this, premised on the inevitability of harmful synthetic chemicals as a part of everyday life, is the film The Devil We Know, which takes its name from DuPont's fifty-year cover-up of the fact that the group of chemicals (per- and poly-fluoroalkyl substances classified as "C8") that make Teflon $®$ and other perfluorooctanoic acid (PFOA) and perfluorinated alkylated substance (PFA) products cause birth defects, based on previously secret DuPont and $3 \mathrm{M}$ documents. ${ }^{113}$ Although DuPont was aware of this fact decades before independent researchers finally indicted these chemicals, ${ }^{114}$ DuPont management resisted replacing it, claiming "C8 is the devil we know", whereas a new chemical ("the devil we don't know") might even be more dangerous. ${ }^{115}$ Certainly, this argument has been made strenuously against banning glyphosate. ${ }^{116}$ But such perhaps deserved fears that if we dispose of current risky chemicals then their replacements could present even greater risks is not only held by chemical manufactures, but also by regulatory bodies. Of course, such logic is premised on the inevitability of continued levels of chemical inputs, rather than scrutinising sceptically the perceived need for their continuance, especially according to business as usual.

Government agencies and regulators, however, do often fall into such frames of inevitability, buying into the actuality rather than the construction of dilemmas of regulating dangerous substances. Such framing is likely influenced by industry and the well-trodden revolving door between government regulation agencies, which are frequently accused of pro-industry thinking at the disservice of environmental protection. ${ }^{117}$ Regulators' perceptions, however unfounded, often collapse into a sense of being trapped, backed into a corner, where they cannot take decisive precautionary action, as if the arrangement of profits and shareholders for corporations, together with industry capture of regulatory agencies, precludes them from autonomous action going against the grain. While such outlooks are understandable, we need to move our

\footnotetext{
112 M Mazzucato, The Entrepreneurial State: Debunking Public vs. Private Sector Myths (London, Penguin Books 2018).

113 S Soechtig and J Seifert, The Devil We Know (Los Angeles, CA, Atlas Films 2019) <http://www.imdb.com/title/ tt7689910/> (last accessed 16 December 2019).

114 G Arenson, "Toxicity of Teflon Dispersing Agents" (Industry Documents Library, 9 November 1961) <https:// www.industrydocuments.ucsf.edu/docs/\#id=snpw0228> (last accessed 14 March 2020).

115 A Playtis, "Toxicity Information - C8" (Chemical Industry Documents, 26 October 1991) <https://www. industrydocuments.ucsf.edu/docs/\#id=fppw0228> (last accessed 14 March 2020).

116 Duke and Powles, supra, note 42.

117 Muilerman, supra, note 17; Allen, supra, note 22; D Pellow, Resisting Global Toxics: Transnational Movements for Environmental Justice (Cambridge, MA, MIT Press 2007); Fagin and Lavelle, supra, note 107; Nestle and Pollan, supra, note 107; N Freudenberg, Lethal but Legal: Corporations, Consumption, and Protecting Public Health (1st edition, Oxford, Oxford University Press 2014).
} 
regulatory institutions out of the realm of resigned determinism and animate them to define themselves as agencies creating coherent policies protecting the public interest. Right now, only a very thin veneer separates regulatory agencies from industry, ${ }^{118}$ without meaningful circuit breakers that alert if a problem occurs. The cooperative model of industry with government has its limits, and at least some agencies need to be adversarial to industry, as Wagner suggests. For any system to achieve resilience, redundancy, slack and flexibility are required. ${ }^{119}$ We need this in our institutions as well, with multiple back-ups in case one agency fails, using precaution and updating policies according to new findings from the field.

Finally, the asymmetry between the economic priorities for chemical manufacturers and farmers bound up in high-input agriculture overshadowing other concerns continues to haunt rational risk regulation and policymaking. Property rights as they have been distributed are framed as sacrosanct, while human rights and biodiversity rights, or rights against ecocide, are framed as aspirational, not yet configured into the balance in cost-benefit analyses. The long-term impact of such short-term thinking requires coordination to rationally reassess this dilemma.

\section{Conclusion}

The interactions between pesticides and water and the theoretical, modelled or otherwise a priori predictions reach their asymptote of explanatory power in the messy world of in situ application. This contribution discussed less the nitty-gritty of the biodiversity impact from a natural science perspective, and instead analysed the discourse and regulatory means surrounding the measurement and assessment of these impacts.

Regulatory bodies have historically been simultaneously very concerned with and very lax regarding chemical pollution in water. We documented that while existing EU laws could be marshalled for strong protection of aquatic environments - even when thresholds are surpassed - little is done to either post facto make amends or preventatively take measures to ensure that such limits will not be breached in the future.

Risk assessment will play a crucial role in the 2022 EFSA decision to deny or renew the continued use of glyphosate in the EU. Especially in light of the - in our opinion - overly dominant focus on whether the chemical is carcinogenic, ${ }^{120}$ we have sought to show the necessity to expand such decisions in order to account for other pertinent factors, such as admixture effects on wildlife and fresh water. Such as an expansion would align with the target of enhancing "policy coherence for sustainable development" called for in Sustainable Development Goal 17.4. It would be a mistake, however, to take an

118 T Clunies-Ross and N Hildyard, The Politics of Industrial Agriculture (Abingdon, Routledge 2013); JL Harrison, "Pesticide Purveyors and Corporate Power" in S Jayaraman and K De Master (eds), Bite Back: People Taking on Corporate Food and Winning (Berkeley, University of California Press 2020) pp 51-62.

119 G Gallopín, "Planning for Resilience: Scenarios, Surprises, and Branch Points" in LH Gunderson and CS Holling (eds), Panarchy: Understanding Transformations in Human and Natural Systems (Washington, DC, Island Press 2002) pp 361-93.

120 Agency for Toxic Substances and Disease Registry (ATSDR), Toxicological Profile for Glyphosate (Draft for Public Comment, Department of Health and Human Services, Public Health Service 2019); L Zhang et al, "Exposure to Glyphosate-Based Herbicides and Risk for Non-Hodgkin Lymphoma: A Meta-Analysis and Supporting Evidence” (2019) 781 Mutation Research 186. 
"innocent until proven guilty" approach with regards to harms, especially in light of the lack of well-established monitoring mechanisms. Because of the insurmountable lag as science catches up with reality, overweighting "evidence-based" policy that requires watertight evidence before limiting the default approval of known problematic pesticides promotes a laissez-faire approach to regulating human and environmental health and creates a smokescreen for not addressing deep-rooted agri-cultural problems. ${ }^{121}$ At best, the glyphosate case presents the opportunity to create a comprehensive chemical framework in the EU focused on precaution rather than adding more ad hoc and insulated evaluations (inviting their own problems) ${ }^{122}$ incrementally tinkering with a process deserving an organised overhaul.

121 Schäfer et al, supra, note 53.

122 S Weber and H Burtscher-Schaden, "Detailed Expert Report on Plagiarism and Superordinated Copy Paste in the Renewal Assessment Report (RAR) on Glyphosate" (2019) <https://www.greens-efa.eu/files/doc/docs/ 298ff6ed5d6a686ec799e641082cdb63.pdf> (last accessed 23 September 2019). 